\title{
Double-pass microkeratome technique for ultra-thin graft preparation in Descemet's stripping automated endothelial keratoplasty
}

This article was published in the following Dove Press journal:

Clinical Ophthalmology

17 March 2012

Number of times this article has been viewed

\author{
Maylon Hsu \\ Walter L Hereth \\ Majid Moshirfar \\ University of Utah, John A Moran \\ Eye Center, Department of \\ Ophthalmology and Visual Sciences, \\ Salt Lake City, UT, USA
}

\begin{abstract}
Endothelial keratoplasty is evolving with increased attention placed on the optical qualities of the posterior donor lenticule. In efforts to improve visual outcomes, the effects of the thickness, smoothness, and planar profile are being studied. This paper describes a double-pass microkeratome technique to create ultra-thin (less than $100 \mu \mathrm{m}$ ) Descemet's stripping automated endothelial keratoplasty grafts.
\end{abstract}

Keywords: ultra-thin, thin, endothelial keratoplasty, microkeratome, double-pass, Descemet's stripping automated endothelial keratoplasty, DSAEK, posterior donor lenticule, eyebank

\section{Introduction}

Endothelial keratoplasty requires the creation of a posterior donor lenticule to replace diseased endothelial cells. Many methods have been described including using manual lamellar dissection, ${ }^{1}$ single $^{2}$ and double-pass ${ }^{3}$ automated microkeratomes and, more recently, femtosecond lasers. ${ }^{4-8}$ Thinner Descemet's stripping automated endothelial keratoplasty (DSAEK) grafts may improve visual outcomes ${ }^{9}$ and possibly reduce the observed postoperative hyperopic shift. ${ }^{10,11}$ We describe refinements to a surgical technique using a double-pass microkeratome system as first proposed by Busin at the American Society of Cataract and Refractive Surgery 2011 Annual Symposium. Using an artificial chamber maintainer with the ability to create a second pass 180 degrees away from the initial pass, the steps to create ultra-thin posterior donor lenticules with a targeted thickness of less than $100 \mu \mathrm{m}$ are described.

\section{Surgical technique}

Human corneoscleral rims are mounted in a single-use artificial anterior chamber designed with a rotating ring guide (Lamellar Keratoplasty System; Moria, Doylestown, PA; see supplementary video). The anterior chamber has two ports. One port is attached to IV tubing connected to a balanced salt solution (BSS) bottle raised on an IV pole. The other port is connected to a $20 \mathrm{cc}$ syringe which is filled with Optisol (Bausch and Lomb, St Louis, MO). With the Optisol stopcock closed, the system is first flushed with BSS by opening the attached stopcock until BSS is seen flowing through the central anterior chamber opening. This stopcock is then turned to the closed position. The Optisol stopcock is then opened, and the Optisol is injected until only Optisol is seen flowing to create a mound for donor tissue placement. The donor cornea is then placed on the anterior chamber while simultaneously injecting Optisol to ensure no bubbles are present (Figure 3A). Excess Optisol is cleaned with a gauze
Correspondence: Majid Moshirfar John A Moran Eye Center, 65 Mario Capecchi Drive, Salt Lake City, UT 84 I32, USA

Tel + I 8015873020

Fax + I 80I 9479286

Email majid.moshirfar@hsc.utah.edu 
sponge to prevent stickiness and a poor fit of the cover. The metal cover is then placed over the cornea, and locked into position once the centering is adequate. Then, the white locking ring is secured and tightened. The Optisol stopcock is then closed. The BSS stopcock is then opened to equilibrate the pressure for a few seconds and then turned to the closed position. The pressure is confirmed to measure $90 \mathrm{~mm} \mathrm{Hg}$ using a Barraquer tonometer. At this step, the BSS bottle height is raised between 1.2-3 meters from the anterior chamber, until the targeted pressure is achieved and equilibrated. This is followed by further tightening of the locking ring. Using a lint-free weck-cell sponge, the cornea epithelium is then removed (Figure $3 \mathrm{~B}-\mathrm{E})$.

Corneal thickness measurements are then performed using an ultrasound pachymeter (Pachette 2; DGH Technology, Exton, PA) in four quadrants at the mid-periphery of the cornea and also centrally (Figure 3F). The thickest quadrant is recorded by making a cap alignment mark with a marking pen. The blue guide ring is then placed over the cornea so that the reference dot is aligned with this mark (Figure 3G). This is done to ensure the thickest part of the cornea is cut first with the microkeratome. The blue locking ring is then secured over the guide ring. The system is equilibrated again by opening the BSS stopcock for a few seconds and then closing it (Figure $3 \mathrm{H}$ ).

Based on the central cornea thickness, the appropriate head is then selected to aim for a residual stromal bed of $220 \mu \mathrm{m}$. For corneas 500-600 $\mu \mathrm{m}$ thick, a $250 \mu \mathrm{m}$ head is used for the first pass. For corneas 400-500 $\mu \mathrm{m}$ thick, a $200 \mu \mathrm{m}$ head can be used and for those less than $400 \mu \mathrm{m}$, a $130 \mu \mathrm{m}$ head is recommended. The appropriate head is then attached to the turbine and the head is lubricated with BSS and checked for oscillations. The head is then docked into position on the guide ring. The surface of the guide ring near the docked head is lubricated with a drop of BSS. A wet Weck-cell is used to hydrate the cornea, avoiding overhydration. The first pass is performed at a constant speed over 4-5 seconds (Figure 4). The anterior cap is removed from the head, set aside, and kept moist with BSS.

The residual stromal bed is then measured. If the residual stromal bed is over $235 \mu \mathrm{m}$, a $130 \mu \mathrm{m}$ head can be used for the second pass. For thicknesses 216-235 $\mu \mathrm{m}$, a $110 \mu \mathrm{m}$ blade is recommended. For thicknesses 190-215 $\mu \mathrm{m}$, a $90 \mu \mathrm{m}$ head may be used. If the cornea is thinner than $190 \mu \mathrm{m}$, a wet weck-cell can be used to gently hydrate the cornea, and the pachymetry can be remeasured. This step can increase the thickness by $20-30 \mu \mathrm{m}$. Alternatively a $50 \mu \mathrm{m}$ head may be used with caution. Prior to the second pass, the blue locking ring must be loosened enough to rotate the guide ring so that the reference dot is positioned 180 degrees away from the alignment mark (Figure 5). This is to decrease the chance of perforating so that the second pass enters at a thicker site of the cornea and to create a more planar graft. The same steps of equilibration of pressure and lubrication of the head and the guide ring are done prior to the second pass. The second pass is performed at a much slower rate, two to three times slower than the first pass to ensure a thin and uniform cut. After the second pass, ultrasound pachymetry usually cannot be performed on very thin residual beds because of inadequate signal registration. Anterior segment optical coherence topography may be used to confirm the residual stromal bed (Figures 1A and 2). The intermediate cap is removed from the microkeratome head and set aside.

After drying the stromal bed, a marking pen is used to mark the outline of the cut. The second pass creates a cut which has a visibly smaller diameter than the first cut, which may generally range from $8-8.5 \mathrm{~mm}$. For these reasons, it is suggested to verify the diameter of the cut with calipers. The first anterior cap only is then replaced on top of the cornea bed, oriented with the previously made alignment mark.

Careful disassembly of the anterior chamber is required to remove the cornea scleral rim atraumatically (Figure 6). After the guide ring and the two locking rings are removed, the BSS stopcock is opened. The metal cover is then rotated back and forth until a small amount of fluid is seen coming out of the base of the anterior chamber. The anterior chamber is then inverted and then the cover is gently removed completely from the base, allowing the force of BSS to prevent the cornea scleral rim from collapsing. From the underside of the metal cover, any conjunctival adhesions to the metal rim are released with forceps. Once freed, the cornea is then gently removed completely from the cover and placed in a moist chamber. It is now ready for the trephine punch of the desired diameter prior to insertion into the recipient.

\section{Discussion}

Endothelial keratoplasty has revolutionized the treatment of endothelial dysfunction. Continued refinements in surgical techniques have led to the replacement of penetrating keratoplasty by DSAEK for treatment of such disorders as Fuch's dystrophy and bullous keratopathy. ${ }^{12}$ In efforts to improve visual outcomes, more attention has been placed on the donor lenticule profile. The non-planar quality of the graft may contribute to the hyperopic shift seen after DSAEK surgery, as well as additive effect of the stroma. ${ }^{10,11}$ The faster and improved visual recovery seen in Descemet's 

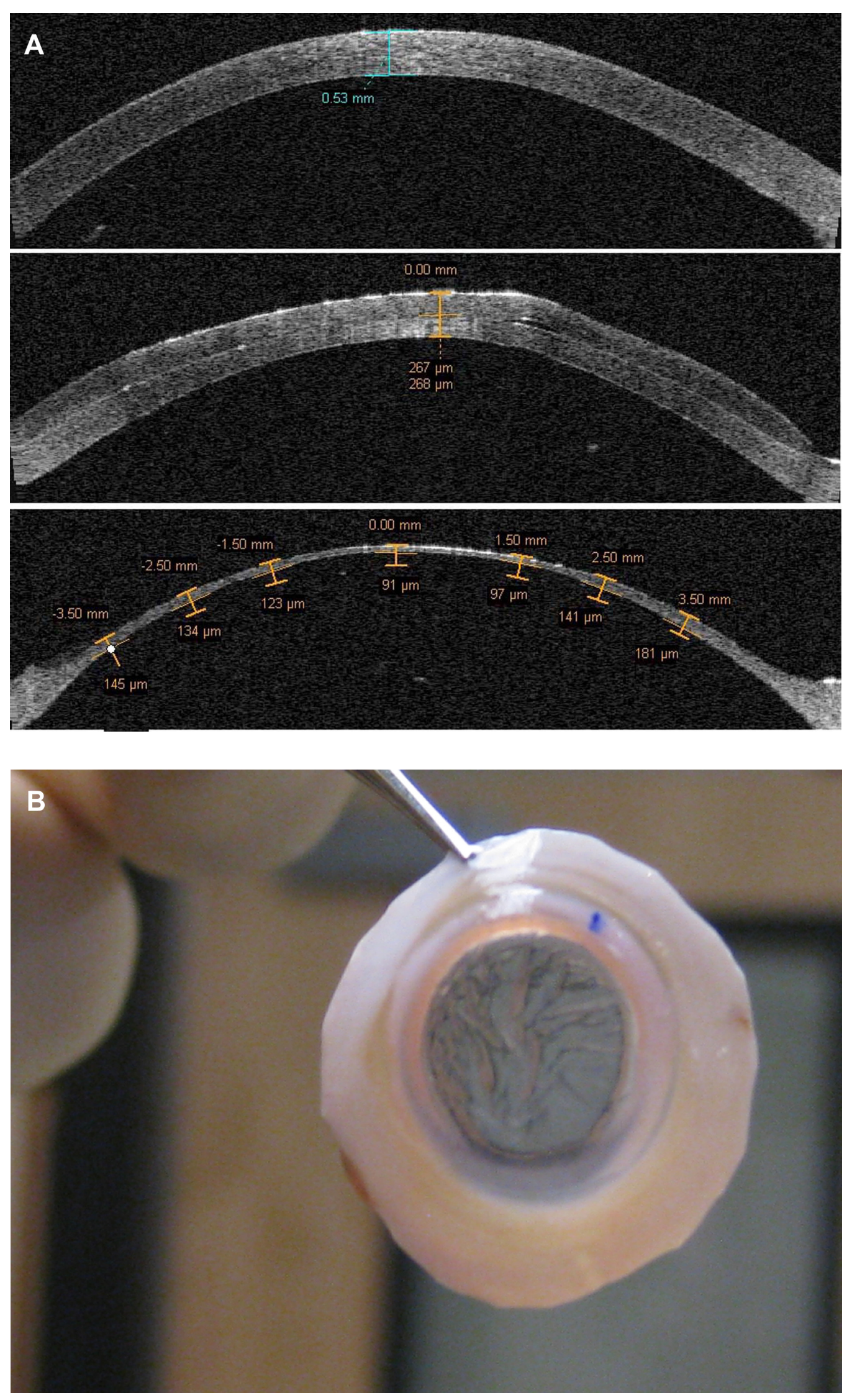

Figure I Visante anterior segment optical coherence tomography image (A) showing initial cornea graft thickness (prior to epithelial removal) (top), after a $200 \mu \mathrm{m}$ head pass (middle), and after the second II $10 \mathrm{~m}$ pass (bottom). After the double-passes, the cornea scleral rim shows striae as evidence of the thinness of less than $100 \mu \mathrm{m}$ (B). 


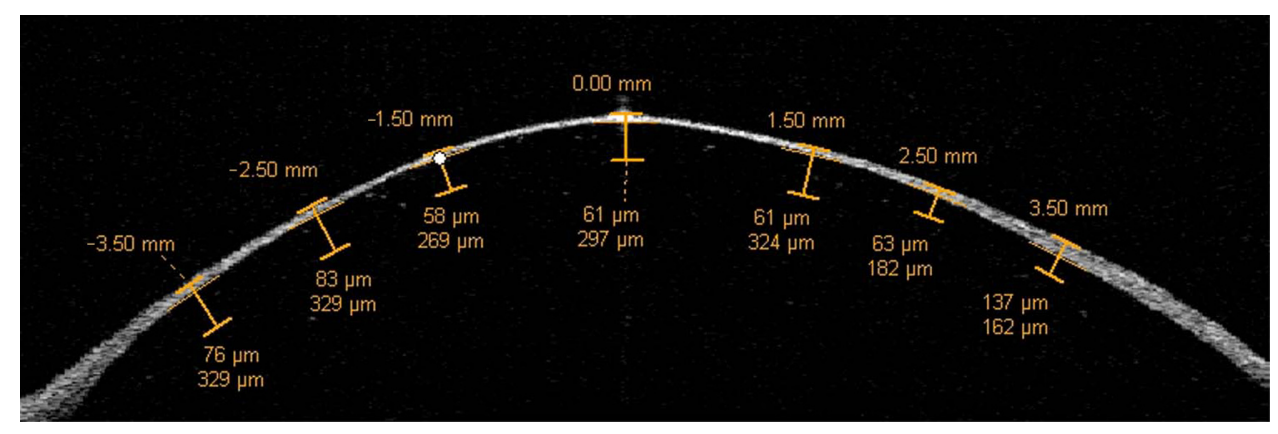

Figure 2 Another anterior segment optical coherence tomography image demonstrating the thinness and smoothness of the graft after a double-pass technique.

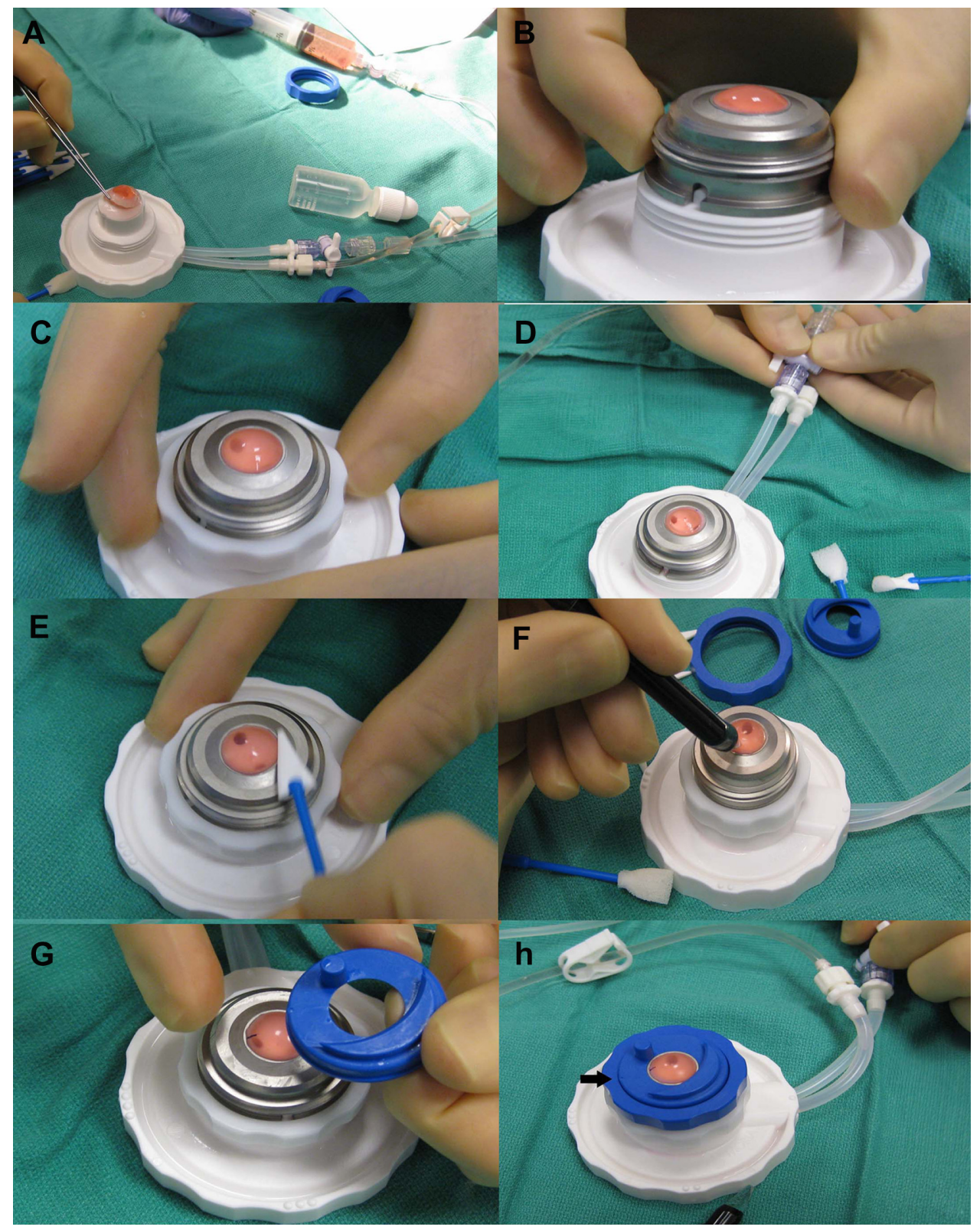

Figure 3 (A) The cornea scleral button is centered on the anterior chamber while infusing Optisol through a syringe. (B) Once centration is achieved, the metal cover is placed over the cornea so that the groove fits into the white notch on the base of the anterior chamber. (C) A white locking ring is then tightened. (D) The balanced salt solution port is opened and then closed to equilibrate the pressure. (E) Epithelium is removed with a Weck-cell. (F) Pachymetry is measured in four quadrants to determine the thickest area of the cornea. (G) The guide ring is oriented so that the reference dot (arrow) is aligned with the alignment mark which is placed in the thickest quadrant of the cornea. $(\mathbf{H})$ The stopcock to the balanced salt solution infusion is opened for a few seconds to equilibrate the pressure again prior to the first pass. 


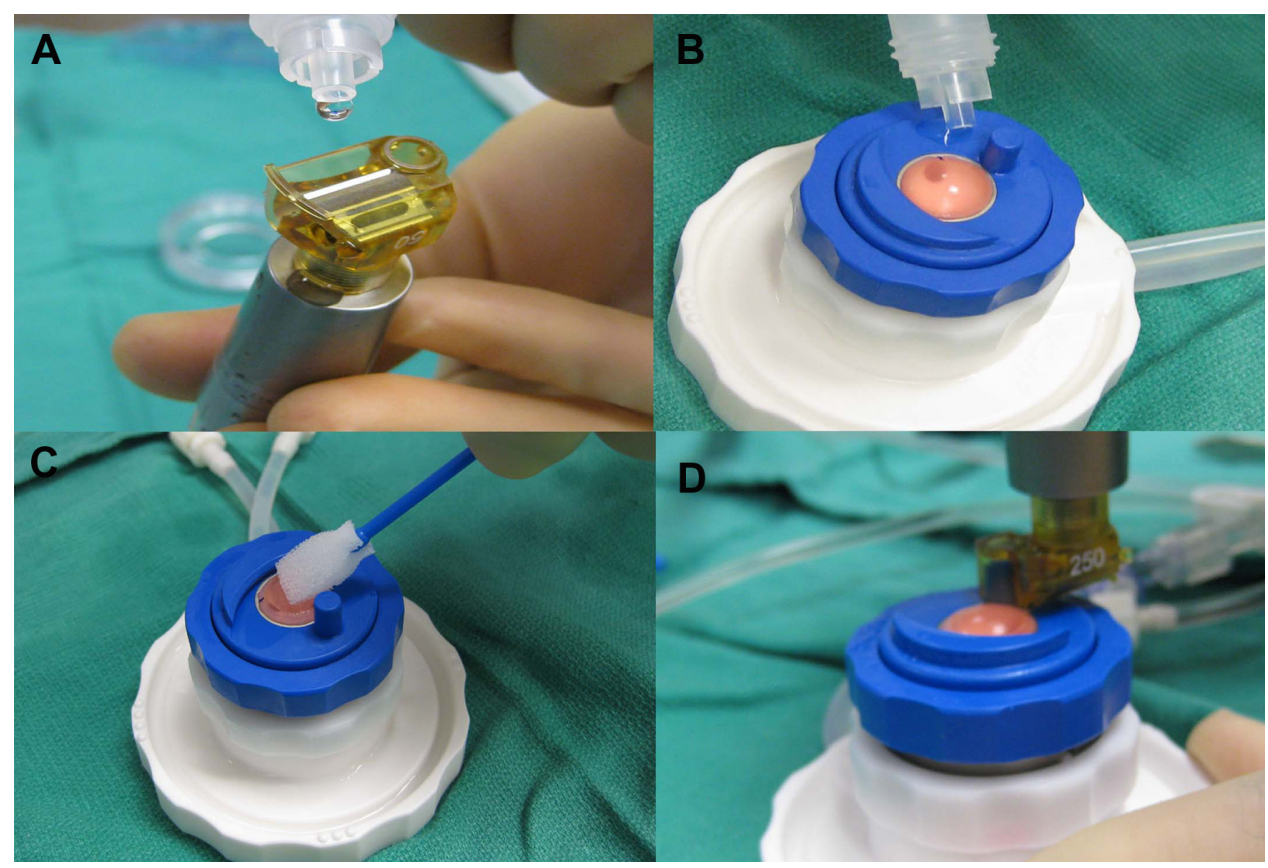

Figure 4 Prior to the initial pass, the microkeratome head is lubricated and checked for oscillations (A). A drop of balanced salt solution is placed on the guide ring near the docking site of the head (B), and a wet Weck-cell is used to gently moisten the cornea surface prior to the first cut (C and $\mathbf{D})$.

membrane endothelial keratoplasty (DMEK) ${ }^{13}$ may be due to the lack of an interface, however it is more technically challenging, often requiring multiple re-bubbling procedures. ${ }^{13}$

In the traditional single-pass technique to create thinner DSAEK grafts, using microkeratome heads greater than
$350 \mu \mathrm{m}$ increases the risk of donor tissue perforation. With such limitations, grafts may routinely be greater than 200-250 $\mu \mathrm{m}$ thick prior to insertion. Although femtosecond lasers have been proposed to create DSAEK grafts, ${ }^{4-8}$ they have not yet been able to produce reliably thin and smooth posterior lenticules. As previously reported, using a double-pass

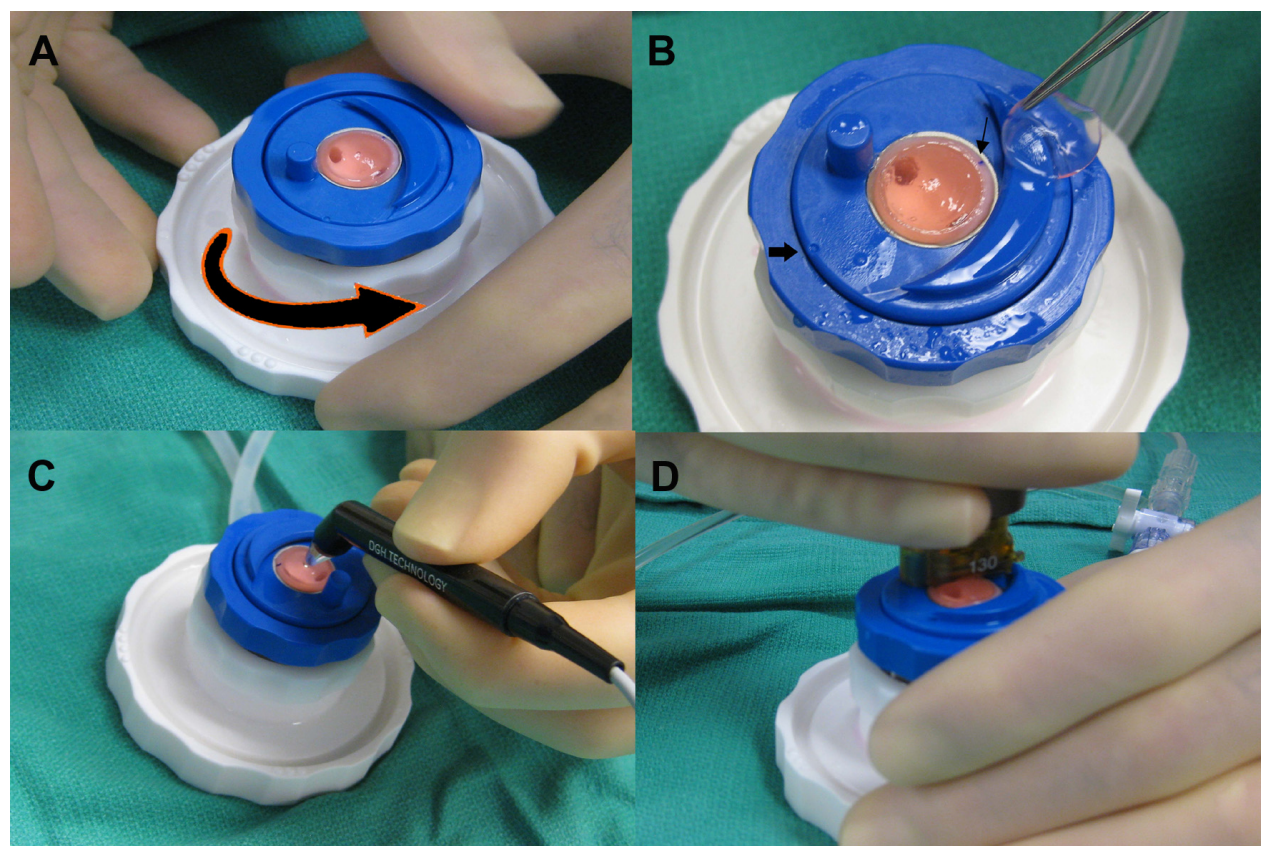

Figure 5 Prior to the second pass, the blue locking ring is loosened so that the guide ring can be rotated (A). The reference mark (thick arrow) is now turned 180 degrees away from the initial alignment mark (thin arrow) (B). Central pachymetry is remeasured (C) prior to the second pass (D). 


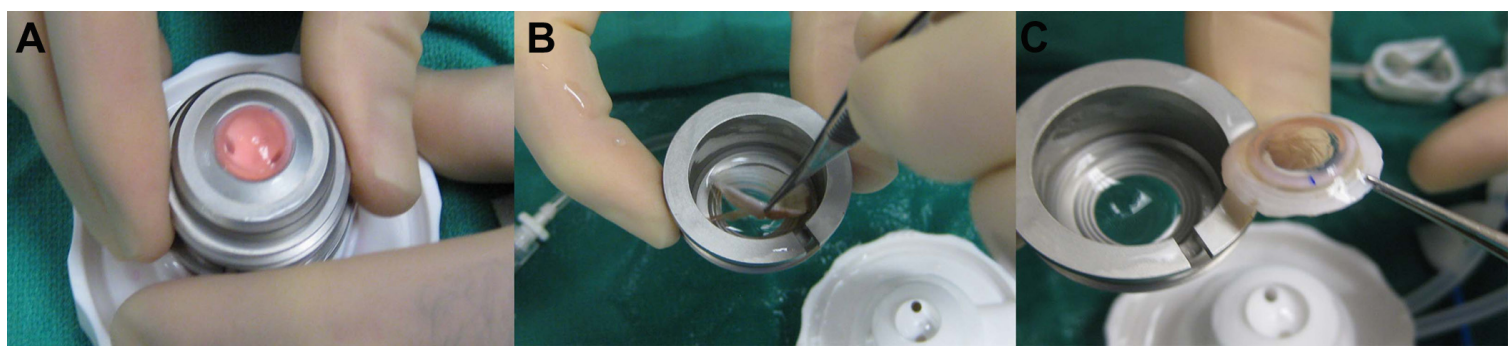

Figure 6 Disassembly of the anterior chamber begins by removing the guide ring, and blue and white locking rings and opening the balance salt solution stopcock. The metal cover is then rocked gently until balance salt solution is seen flowing $(\mathbf{A})$. The entire apparatus is then inverted and the cover removed. Forceps are used to release any conjunctival adhesions (B) prior to removing the cornea scleral rim from the underside of the metal cover (C).

technique with the standard non-disposable microkeratome system may result in donor tissue perforation. ${ }^{3}$

In the present study, using a specially designed artificial anterior chamber with a rotatable guide ring allows a second pass to be started 180 degrees away from the initial entry point of the first pass. With this modification, entering at a thicker area of the cornea decreases the chance of perforation and aids in creating more planar grafts. Special attention must be made to ensure the artificial chamber is adequately pressurized with a separate infusion connected to a BSS bottle raised on an IV pole. Additionally, the speed of the second pass should be done at a much slower rate than the first pass to ensure a thinner and smoother cut.

In trials of donor corneas that were greater than $600 \mu \mathrm{m}$, we experienced several perforations. Since epithelial sloughing may greatly contribute to edema and increased thickness, it is important to remove the epithelium prior to measuring central cornea thickness. Donor corneas with a thickness greater than $600 \mu \mathrm{m}$ may not be suitable for a double-pass technique as this may indicate stromal swelling with poor predictability of depths of microkeratome cuts. This may limit donor tissue availability for those surgeons who may request thinner tissue. Using a $300 \mu \mathrm{m}$ or $350 \mu \mathrm{m}$ head may be attempted in more edematous tissue, greater than $600 \mu \mathrm{m}$, with a more conservative depth of cut for the second pass.

Another disadvantage of the double-pass technique is that the second pass may create a smaller diameter cut. Often the largest diameter punch for a given recipient cornea is used to provide more endothelial cells to be transplanted. Significantly smaller diameters may be attributed to insufficient re-pressurization of the anterior chamber prior to cuts or over-tightening of the white locking ring that may cause the cornea to artificially flatten. A caliper to measure the diameter of the final cut and marking the outline of the cut can help in planning the ideal trephine punch size. The thinner tissue may be more difficult to surgically manipulate, especially if a forceps folding technique is used. Microstriae may be seen when transporting the thin graft tissue and BSS hydration to keep the graft flat is helpful. The mini-Busin glide (Moria, Doylestown, PA) has a wider loading platform to aide in graft insertion for these reasons. Once inside the anterior chamber, the graft unfolds like any DSAEK lenticule with some degree of stromal support, without the scrolling and positioning challenges seen with DMEK tissue.

Although several studies have found no correlation between visual outcomes and thickness of posterior donor lenticules, ${ }^{1,14,15}$ the range of thickness studied was variable. With stricter criteria, Neff et $\mathrm{al}^{9}$ found that thinner DSAEK grafts (equal or less to $131 \mu \mathrm{m}$ ) had better visual outcomes than thicker grafts when measured at an average of 1 year after surgery. More research is needed to determine if there is an ideal thinness of a graft that may emulate the outcomes of DMEK, without the risks of wasted donor tissue during preparation. It is unknown if a thicker graft has the potential to achieve the same postoperative thinness as an initially thinner created graft. The reproducibility and predictability of the double-pass technique also needs to be validated with further studies to assess long-term visual outcomes.

\section{Acknowledgments}

The authors would like to thank Chris McGriff for his major contributions to this work.

\section{Disclosure}

Funding was provided from the Research to Prevent Blindness Foundation (New York, NY). The authors have no financial interests in any materials or products discussed in the manuscript or any other disclosures.

\section{References}

1. Price MO, Price FW Jr. Descemet's stripping with endothelial keratoplasty: comparative outcomes with microkeratome-dissected and manually dissected donor tissue. Ophthalmology. 2006;113(11):1936-1942.

2. Gorovoy MS. Descemet-stripping automated endothelial keratoplasty. Cornea. 2006;25(8):886-889. 
3. Sikder S, Nordgren RN, Neravetla SR, Moshirfar M. Ultra-thin donor tissue preparation for endothelial keratoplasty with a double-pass microkeratome. Am J Ophthalmol. 2011;152(2):202-208.e2.

4. Cheng YY, Pels E, Nuijts RM. Femtosecond-laser-assisted Descemet's stripping endothelial keratoplasty. J Cataract Refract Surg. 2007;33(1): $152-155$.

5. Jones YJ, Goins KM, Sutphin JE, Mullins R, Skeie JM. Comparison of the femtosecond laser (IntraLase) versus manual microkeratome (Moria ALTK) in dissection of the donor in endothelial keratoplasty: initial study in eye bank eyes. Cornea. 2008;27(1):88-93.

6. Mehta JS, Shilbayeh R, Por YM, Cajucom-Uy H, Beuerman RW, Tan DT. Femtosecond laser creation of donor cornea buttons for Descemet-stripping endothelial keratoplasty. J Cataract Refract Surg. 2008;34(11):1970-1975.

7. Monterosso C, Fasolo A, Caretti L, Monterosso G, Buratto L, Bohm E. Sixty-kilohertz femtosecond laser-assisted endothelial keratoplasty: clinical results and stromal bed quality evaluation. Cornea. 2011;30(2):189-193.

8. Rousseau A, Bensalem A, Garnier V, et al. Interface quality of endothelial keratoplasty buttons obtained with optimised femtosecond laser settings. Br J Ophthalmol. 2012;96(1):122-127.

9. Neff KD, Biber JM, Holland EJ. Comparison of central corneal graft thickness to visual acuity outcomes in endothelial keratoplasty. Cornea. 2011;30(4):388-391.
10. Yoo SH, Kymionis GD, Deobhakta AA, et al. One-year results and anterior segment optical coherence tomography findings of descemet stripping automated endothelial keratoplasty combined with phacoemulsification. Arch Ophthalmol. 2008;126(8):1052-1055.

11. Holz HA, Meyer JJ, Espandar L, Tabin GC, Mifflin MD, Moshirfar M. Corneal profile analysis after Descemet stripping endothelial keratoplasty and its relationship to postoperative hyperopic shift. J Cataract Refract Surg. 2008;34(2):211-214.

12. Lee WB, Jacobs DS, Musch DC, Kaufman SC, Reinhart WJ, Shtein RM. Descemet's stripping endothelial keratoplasty: safety and outcomes: a report by the American Academy of Ophthalmology. Ophthalmology. 2009;116(9):1818-1830.

13. Ham L, Dapena I, van Luijk C, van der Wees J, Melles GR. Descemet membrane endothelial keratoplasty (DMEK) for Fuchs endothelial dystrophy: review of the first 50 consecutive cases. Eye (Lond). 2009;23(10):1990-1998.

14. Terry MA, Shamie N, Chen ES, Phillips PM, Hoar KL, Friend DJ. Precut tissue for Descemet's stripping automated endothelial keratoplasty: vision, astigmatism, and endothelial survival. Ophthalmology. 2009;116(2):248-256.

15. Nieuwendaal CP, van Velthoven ME, Biallosterski C, et al. Thickness measurements of donor posterior disks after descemet stripping endothelial keratoplasty with anterior segment optical coherence tomography. Cornea. 2009;28(3):298-303. 


\section{Supplementary data}

Supplementary video: Demonstration of the double-pass microkeratome technique for ultra-thin graft preparation in DSAEK

http://dvpr.es/xV5eWG

\section{Publish your work in this journal}

Clinical Ophthalmology is an international, peer-reviewed journal covering all subspecialties within ophthalmology. Key topics include: Optometry; Visual science; Pharmacology and drug therapy in eye diseases; Basic Sciences; Primary and Secondary eye care; Patient Safety and Quality of Care Improvements. This journal is indexed on
PubMed Central and CAS, and is the official journal of The Society of Clinical Ophthalmology (SCO). The manuscript management system is completely online and includes a very quick and fair peer-review system, which is all easy to use. Visit http://www.dovepress.com/ testimonials.php to read real quotes from published authors. 